\title{
SOME NOTES ON
}

\section{PROGNOSIS IN CASES OF PAIN OVER THE HEART.}

\author{
BY ARTHUR J. HALL, M.A., M.D., D.Sc., F.R.C.P. \\ Emeritus Professor of Medicine, University of Sheffield.
}

Amongst the more common conditions in which prognosis is always important and often difficult, is that in which the patient complains of "pain over the heart".

This somewhat vague definition is used purposely, because a pain anywhere in this region usually receives more attention than even more severe pain in other parts of the body, and in consequence medical advice is more quickly sought.

In many of such cases it is soon evident to the medical man that the pain is not cardiac at all and is of no serious importance. In these cases, however, perhaps more than in any other type, prognosis is important because it is essential that the patient should be convinced that there is nothing wrong with his heart. This cannot be done unless the assurance is given with absolute confidence, and such confidence requires certainty of diagnosis. The least doubt, the slightest hesitation on the part of the medical man in stating his conclusions, may easily be the starting point of a life-long semi-invalidism. In other cases, however, it is difficult, even after careful investigation, to be sure about the origin of the pain or its importance. In these circumstances the importance of prognosis is obvious.

I am not here referring to cases with definite heart lesions or to subjects of recognised old-standing valvular disease, nor to typical cases of severe angina of effort, nor to a well-marked syndrome of coronary thrombosis, but rather to the less severe and more vague cases of precordial pain especially when brought on by exertion. There may be no shortness of breath, no palpitation or other symptom. The person affected tells you that directly he walks up a slight incline, or has to increase his pace on the level, he begins to have an uncomfortable feeling over the front of his chest which is only relieved by standing still or by going more slowly. Sometimes persons giving a history neither more nor less than this become quickly worse, the pain comes on more severely with less exertion and a fatal end is not far off. In others the condition remains unchanged for years. How are they to be distinguished?

Lewis ${ }^{(1)}$ in his recent text-book gives the expectation of life in early cases of " angina of effort" as about ten years, whilst in cases where there is "angina of effort on walking a short way" it is about three to six years. But he adds, "It is not intended that this table shall form a precise guide to prognosis in individual cases, each of which must be considered on its own merits!" (The italics are mine). This point is admirably emphasised throughout the book. It means that in each case every available method of examination of the individual must be made and a general survey of the findings carefully weighed before an opinion is formed as to the gravity or otherwise of this precordial pain on effort.

In January, I93I, when going through some of my case records extending over a considerable number of years, it seemed desirable to follow up such cases as had consulted me chiefly for this symptom-precordial pain. I was able to get reliable information concerning fifty-one of them-39 were men and I2 women. They covered a period of 30 years, I898 to 1928 . 


\section{Mortality.}

I do not propose to give any detailed account of the results. Thirty-five of them were dead, and the dates of their deaths showed that in most cases they had not exceeded the span of life as given in Lewis's tables. Sixteen, however, were still alive. Of these four had only been seen less than five years ago and need not be considered now. On the other hand, twelve are still living, at periods of from over 6 to over 20 years.

\section{Age of incidence of Cardialgia.}

Of the twelve patients who were living more than six years after the commencement of symptoms it is noteworthy that in six of them the onset of precordial pain was between 30 and 40 years of age. Indeed, none of the six cases in which the pain was first complained of before 40 years of age had died. They had lived 24, $22,21,20$, IO, and 4 years respectively.

In three of the cases the onset was between 40 and $50-$ all of these had diedbut one woman had lived 22 years, dying eventually of Paget's disease, and one man had lived for more than I5 years.

In the group in which the pain began between 50 and 60 years of age there were twenty-five, nineteen men and six women. Of these nine men were still living. All the women had died.

All the patients in whom the pain began over 60 years of age had died except one-and he had only developed the symptoms within a year of my seeing him.

These figures must only be considered as rough guides. In the natural course of events the prospect of life is diminishing with each decade. The follow-up of these cases shows, however, that in a certain number of those still living the "precordial pain" was not of serious character. In all probability had the methods of investigation, which are now in daily use, been then available, their true nature would have been clear at the time, and prognosis would have been more accurate. But, judged by these cases alone, it would seem that in arriving at a prognosis in cases of precordial pain, the question of the patient's age at onset is a factor which must be considered, and that the earlier it occurs the less serious is the outlook. Yet there are one or two cases in my series which, if they presented themselves to-day, would make me hesitate in giving a prognosis.

The following are brief records of some of these.

CASE I.-Mr. B., 38 years of age, a business manager, consulted me first in I9I2, complaining that for a week or two he had suffered from pain in the front of the chest when walking up a slight incline. He had had syphilis when 20. The blood gave a positive Wassermann reaction. The blood pressure was slightly raised.

During the next few years I saw him occasionally, the precordial pain on walking up a slight incline remained unchanged. He suffered from attacks of articular gout; he had had an attack of renal colic with hæmaturia followed by the passage of two or three calculi; there had also been an attack of severe facial neuralgia. He 
had to give up his work about six years ago. I saw Mr. B. again a few months ago. His condition was unchanged. An electrocardiogram showed "some slight left sided preponderance and a general poverty of excursions in all leads, nothing else." There have been no indications of gallstones in his case.

To-day his condition is very little different from what it was twenty years ago. He still gets precordial pain of considerable severity if he exerts himself beyond a certain limited extent, but provided he keeps within such limits he is comfortable. He gets relief from Nitrite of Amyl capsules. He eats well, sleeps well, and looks well.

I may say that when this man first consulted me twenty years ago I formed a very unfavourable opinion of him, and at my suggestion he consulted more than one prominent authority on heart disease. From their letters to me I know that their prognosis was similar to mine. None of us thought he would be living twenty years later, apparently but little the worse.

CASE II.-Another case in which I felt quite uncertain as to the prognosis, was the following.

Mr. J. consulted me in May, Igr3. He was then 55 years of age. He had always been a very active and keen sportsman. In I902-when he was 44-he was hit over the heart by a cricket ball. (There would seem to have been "body-line bowling " even in those days). After that he began to have severe pain over the precordium and down the left arm on exertion. He improved after a long rest, but ever since he has had the following symptoms:

When he starts to walk, any extra exertion, especially on going up a slight incline, brings on precordial pain which gradually gets worse until he has to stop. After this has been repeated a few times the pain goes off entirely and he is able to carry on without difficulty. Thus on a day's shooting, of which he is very fond, in the morning he has to keep stopping at short intervals, but once he has got over that he can keep up with the rest of the party without difficulty until lunch time. After resting during the lunch interval, the same process has to be gone through when he starts on the afternoon shoot. He not only shoots regularly but he follows the beagles.

When I saw him the pain was becoming more troublesome-a slight incline, a strong wind against him, or any attempt to quicken his pace or to talk whilst walking brought on the pain at once.

This man began with his pain when 44 years of age, I saw him when he was 55 and he lived for another six years-that is, seventeen years in all. I have not been able to get any information as to the cause of his death or the character of his last illness. Lewis (2) referring to this type of case says, "Some patients speak of being able, by continuing to exercise, to rid themselves of pain; but this is uncommon."

CASE III.-E. N., a man aged 54, consulted me on January Ist, IgI6, with a history that two weeks before, whilst in the street, he had a sudden attack of "cramp" over the front of the chest and down the left arm. It lasted about ro minutes. Since then he has had several similar attacks, one very severe whilst in bed, another when hurrying up a hill. 
No signs of cardio-vascular disease were found. I did not see or hear of him again until January, I93I-that is, fifteen years later. His general condition seemed much the same. The attacks of pain still occurred. They began in the left arm and hand, passing upwards to the side of the chest "like a vice". They developed on any sudden exertion such as getting into bed. They were worse if he took walking exercise after a meal. They were relieved by capsules of Amyl Nitrite. The report of an electrocardiogram, taken on March I6th, I93I, was as follows:- "The Q.R.S. interval exceeds I/Io sec. Left ventricular preponderance."

An interesting point in his history is that in 1928 , he had also acute abdominal pains and was operated on for "acute pancreatitis". This had been preceded for nine months by "a new pain -more in the stomach". At operation the head of the pancreas was very hard; there was blood-stained free fluid in the peritoneum, and a suppurative gall bladder containing a large number of stones. Although these have been removed, the old attacks of pain continue, though he admits they are not so severe as before.

The connection between pain of anginal character and the presence of gallstones has recently been fully considered by $\mathrm{C}$. $\mathrm{H}$. Miller $^{(3)}$ who makes out a strong case for the view that some patients with what has been suspected to be cardiac pain are really suffering from gallstones, the removal of which puts an end to the attacks.

In the case quoted above it would be pleasant to think that such was the connection of events, but unfortunately removal of the gallstones has not abolished the attacks of pain on exertion, although the patient thinks they are less severe. One must assume that in this case the gallstones were not the whole source of the trouble. It is worth remembering that this man, with rather severe anginal pain on exertion beginning at 54 years of age, could undergo and survive a very serious operation at 65 and be none the worse for it four years later. To-day he is on the whole a well-preserved man of nearly 70 .

CASE IV.-Mr. R. aet. 5I, was seen in December, IgI9. He had had his appendix removed in 1899 .

In July, I9I9, while out for a drive, he had acute pain over the heart with dyspnoea-he thought he would die. The pain lasted an hour.

The second attack occurred four weeks previously, lasting Io minutes. The third occurred the day previous to being seen by me. He was cyanosed. The pulse was irregular, then disappeared. Morphia was given and the pulse returned.

The attacks begin by his eyes going filmy and he can see nothing. He cannot lie down in an attack but must be upright. The pain is down the left side but does not go into the arm.

During my visit he suddenly began to sob, saying that another attack was coming on. I felt his pulse during the attack. It hardly changed at all. He stopped speaking but did not change colour. It passed off and he said his sight had not been affected. My impression was that his pain during that attack was not really intense. I am not prepared to say what was its exact nature. There were no clinical signs of cardio-vascular disease. 
I heard no more of him until I93I-but he was then still alive-that is I2 years later.

CASE V.-Mr. Sp., aet. 52, was first seen in September, r9I8. His first attack of "pain round the heart" came on suddenly whilst in his doctor's surgery. It was very severe and lasted I5 minutes. Since then he has had many attacks.

There was no clinical evidence of cardio-vascular disease. In January, I93I, I saw him again. He had suffered from attacks of similar pain ever since. Three years previously he had a very bad attack - the pain was extremely severe. Sometimes it came in the early mornings. He got it badly after hurrying to catch a tram. An electrocardiogram taken in I93I showed a rather low electrical potential. My prognosis in I9I8 was a bad one, but he has managed to carry on for more than I3 years.

CASE VI.-Mr. F., aet. 55, consulted me in June, I9I5. On May 26th after bending and getting up he had an acute gripping pain in the front of the chest, also down the left arm along the inner side, down to the lower third of the forearm. It lasted about three-quarters of an hour. There was no evidence of cardio-vascular disease.

Sixteen years later his doctor writes, "Mr. F. is still living. He has only had slight attacks until two years ago, since when he has had six or seven bad attacks, one very severe three months ago."

On looking back at this case there are certain points in the history supplied by the patient, which suggest that this was not cardiac pain. Thus in the first place he described the pain as "like knives going into him" ; secondly it lasted for threequarters of an hour-getting steadily more severe; and finally it had nothing to do with effort. Looking back I should suspect that this was probably a case of gallstone colic.

Charlton Briscoe ${ }^{(4)}$ has recently called attention to certain cases of " pain over the heart on exertion" in which the trouble arises in a faulty use of some of the thoracic muscles. In such cases, if suitably treated, the prognosis is favourable. Whether any of the above cases could have borne such an interpretation must remain uncertain.

It is only by reviewing old case records in which at the time there was considerable doubt as to the diagnosis and prognosis that one realises fully the extraordinary extent to which, not only the means of diagnosis in cardiac disorders has increased, but also the much wider outlook which this has given of the cardio-vascular system as a whole. But even with all these aids prognosis in this type of case is sometimes difficult.

(1) Lewis, Sir Thomas. Diseases of the Heart, London, 1933.280.

(2)

loc. cit. p.s1.

(3) Muller, C. H., Lancet, 1932, 1.767.

(4) Charlton Briscoe. Lumleian Lectures. Lancet 1927 1. 637. 749. 857. 